\title{
Analysis on the Influence Factors of High School Students Participating in Paid Remedial Classes
}

\author{
Tinghuan Wang, Xinyue Zhang \\ Statistic Institute, Shanxi University of Finance and Economics, wucheng road, Taiyuan, China
}

Keywords: high school, paid remedial class, factor analysis, logistic regression

\begin{abstract}
With the development of education in China, education spending has become an irreplaceable part of household spending. At present, China's test-oriented education system is still based on scores. Under the pressure of the college entrance examination, the phenomenon of paid remedial class in high school has become a common practice. In order to explore the influencing factors of high school students' participation in paid remedial classes, the high school students from six administrative divisions in Taiyuan City, Shanxi Province participated in the empirical analysis of paid remedial class's data. Based on the reliability and validity, this paper conducts SMOTE processing and factor analysis, and establishes a logistic regression model. From five aspects, it explains the reasons why high school students participate in paid remedial classes, and makes reasonable suggestions for managing paid remedial class.
\end{abstract}

\section{Introduction}

In recent years, the problem of paid remedial classes has become increasingly prominent. Some teachers in order to pursue fame and fortune are keen to pay for remedial classes and take their own jobs in the school as a sideline, affecting the quality of education and teaching and undermining educational equity. In particular, high school students have a lot of competitive pressures, and teachers have higher incomes for replenishing classes. Supplementary classes increase students' learning pressure and bring economic pressure to students' families. The problem of paid remedial classes has been ranked first in letters and visits for six consecutive years. On June 29, 2015, the Ministry of Education issued the "Regulations on the Prohibition of Supplementary Classes for Primary and Secondary Schools and In-service Primary and Secondary School Teachers", which clearly stipulates that it is strictly forbidden for in-service primary and secondary school teachers to organize, recommend and induce students to participate in paid remedial classes both inside and outside the school. However, the phenomenon of paid remedial classes exist despite repeated prohibitions, becoming an open secret, and even a high-priced situation. In this paper, high school students from six administrative divisions in Taiyuan City, Shanxi Province was selected as respondents, and factor analysis and logistic regression models were established by collecting questionnaire data. It is concluded that the paid remedial class of high school students and the comprehensive quality of teachers are significantly related. Combining the actual situation of high school students in Taiyuan City with the reality of paid remedial classes, it provides suggestions for the management of in-service teachers to pay for remedial classes. 


\section{Sampling and data analysis}

\subsection{Sampling situation}

We distributed a total of 585 valid questionnaires by sending questionnaires to high school students in Taiyuan City using simple random sampling combined with stratified sampling. The five administrative districts in Taiyuan are: Yingze District (6 schools, a total of 148), Xiaodian District (6 schools, a total of 168), Xinghualing District (6 schools, a total of 168), Wanbailin District (5 schools, a total of 171), Jiancaoping District (3 schools, a total of 103), Jinyuan District (1 school, a total of 34). Samples are taken in proportion to the number of high schools included in each region.

\subsection{Data analysis}

By selecting high school students from five administrative divisions in Taiyuan City, Shanxi Province, through questionnaire surveys of high school students, noise processes and outliers elimination, 585 valid questionnaires were selected for analysis to ensure the validity and credit of the analysis. The validity and creditworthiness of 585 data. The reliability test requires Cronbach's alpha coefficient to be as close as possible to 1 . After the reliability test of SPSS 25.0, the alpha coefficient of Cronbach of the scale dimension of 10 sub-items is greater than 0.7 , indicating that the reliability of the scale is acceptable. The KMO value of the questionnaire was 0.789 , which was greater than 0.7 , indicating that the questionnaire has high utility.

\section{Model building}

\subsection{Variables and meaning}

Table 1 Variables and meaning

\begin{tabular}{cc}
\hline \multicolumn{1}{c}{ meaning } & Variables \\
\hline Whether to participate in paid extracurricular classes & participate \\
\hline Students' evaluation of the teacher about the teacher's morality & evaluation \\
\hline Teacher's teaching ability & ability \\
\hline Parental education & parents \\
\hline The degree of preparation for the teacher's class & preparation \\
\hline Teacher's responsibility to the class & responsibility \\
\hline Student satisfaction with teacher teaching methods & satisfaction \\
\hline Does the teacher treat students equally? & equal \\
\hline School is public or private & school \\
\hline Whether students are busy in their work & busy \\
\hline
\end{tabular}

\subsection{Data preprocessing}

The SMOTE oversampling algorithm is used to process the unbalanced data, and the R software ROSE package is used to correct the original data sample size, so that the sample size of the paid remedial class reaches a consistent level.

$$
X_{\text {new }}=X+\operatorname{rand}(0,1) *\left|X-X_{\text {near }}\right|, X_{\text {near }} \text { is the Euclidean distance of } \mathrm{X}
$$

For the balanced data, use SPSS25.0 to analyze the factors of whether students participate in paid remedial classes. Dimension reduction of high-dimensional data, and removal of multi-collinearity 
existing in the data, the pattern in the data is found, and the component eigenvalue and component variance contribution rate are obtained. According to the actual situation, five common factors were extracted, and $89.943 \%$ of the total variation was explained. Factor analysis works well. According to Table 2, the load distribution of each factor in five factors can be seen to determine the nature of the information contained in each factor.

Table 2 Rotated Component Matrix ${ }^{a}$

\begin{tabular}{llllll}
\hline Component & 1 & 2 & 3 & 4 & 5 \\
\hline effort & -.009 & .806 & .076 & .090 & .174 \\
preparation & .840 & .006 & .121 & -.063 & .040 \\
satisfaction & -.001 & .050 & .877 & .022 & -.084 \\
equal & .173 & -.402 & .516 & -.149 & -.035 \\
evaluation & .830 & -.090 & .081 & -.149 & .006 \\
school & -.109 & .004 & -.094 & .072 & .925 \\
parents & .059 & .004 & .074 & .873 & .166 \\
busy & .048 & .737 & -.129 & -.126 & -.193 \\
ability & .783 & .081 & -.048 & .111 & -.230 \\
responsibility & .286 & .013 & .380 & -.591 & .175 \\
\hline
\end{tabular}

The coefficient matrix corresponding to each index obtained is the obtained eigenvector matrix, and the independent variables are standardized to obtain five main factors.

$$
\begin{gathered}
Z_{\mathrm{i}}=\beta_{1} * \text { effort }+\beta_{2} * \text { prepare }+\beta_{3} * \text { satisfaction }+\beta_{4} * \text { equal }+\beta_{5} * \text { evaluate }+\beta_{6} * \text { school } \\
+\beta_{7} * \text { parents }+\beta_{8} * \text { busy }+\beta_{9} * \text { faculty }+\beta_{10} * \text { responsible }
\end{gathered}
$$

factor analysis load space map is shown on Figure1:

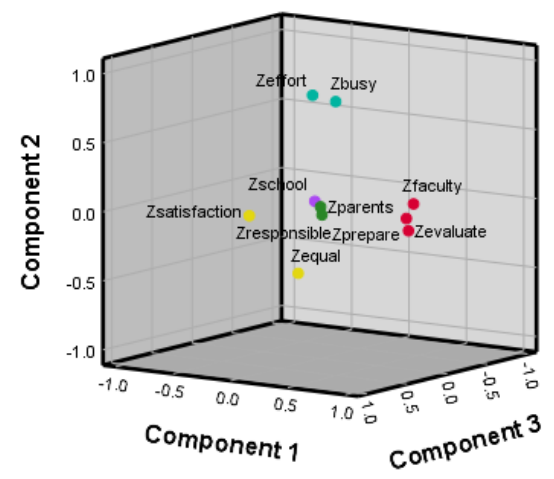

Figure 1 Component Plot in Rotated Space

The Figure1 shows the five common factors extracted. These factors are in turn the overall quality of the teacher, the level of personal effort, the satisfaction of the student with the teacher, the influence of the parents, and the type of school. 


\subsection{Logistic regression analysis}

In order to explore how the five factors affect high school students to participate in paid remedial classes, this paper applies SPSS25.0 Logistic to the regression of five main factors, and estimates the factor score coefficients. The impact of different influencing factors on paid remedial class is reflected in Table 3.

Table 3 Variables in the Equation

\begin{tabular}{|c|c|c|c|c|}
\hline & & B & S.E.Wald & dfSig. $\operatorname{Exp}(B)$ \\
\hline \multirow[t]{6}{*}{ Step 1a } & $\mathrm{Z1}$ & -.569 & .07360 .741 & 1.000 .566 \\
\hline & $\mathrm{Z} 2$ & .293 & 08412.176 & 1.0001 .340 \\
\hline & Z3 & .308 & .09111 .324 & 1.0011 .360 \\
\hline & $\mathrm{Z} 4$ & -.302 & 1028.718 & 1.003 .739 \\
\hline & $\mathrm{Z} 5$ & .352 & 10810.573 & 1.0011 .421 \\
\hline & \multicolumn{4}{|c|}{ Constant-1.198.111116.2851.000.302 } \\
\hline
\end{tabular}

The test results showed that under the significance level of 0.05 , the five principal components all had significant effects on the dependent variables.

The Logstic regression model is:

$$
\log \frac{P}{1-P}=-1.198-0.569 z_{1}+0.293 z_{2}+0.308 z_{3}-0.302 z_{4}+0.352 z_{5}
$$

The comprehensive quality of potential exogenous variable teachers has the greatest influence on whether high school students participate in extracurricular remedial classes, including the fullness of teachers' preparation, teaching ability and teachers' morality. Among them, the sufficient degree of preparation in teachers' classroom is the most important aspect of teachers' comprehensive quality. The degree of personal effort of potential exogenous variables, the degree of student satisfaction with teachers, the influence of parents and the type of school have a greater impact on whether high school students participate in extracurricular remedial classes.

\section{Conclusion and suggestion}

Education administrators can solve the problems of paid remedial classes by improving the above five aspects.

The sufficient degree of preparation in the teacher's classroom is the most important aspect of the teacher's comprehensive quality. Relevant institutions should strengthen the teacher assessment management system, so that the teacher's classroom content is full and comprehensive, and reduce the paid remedial class for the occurrence.

High school students have heavy learning tasks and high competitive pressures. Individuals are generally more concerned about learning. The average level of personal effort reaches $66.7 \%$ of the total value. This is one of the reasons why high school extracurricular tuition is high and the frequency is high.

Education managers can use predictive models to predict the frequency of high school students' participation in paid remedial classes through indicators, reflecting the problems that teachers have in school.

School education should be comprehensively improved and improved. Schools and teachers should try their best to make up for the shortcomings, focus on the classroom, and strengthen contact and communication with parents and students. 


\section{References}

[1]Stevenson, Becker. Shadow Education and Allocation in Formal Schooling: Transition to University in Japan [J]. American Journal of Sociology, 1992(6):1637-1657.

[2] Yang Chun. The ethical and contractual game between teachers and students in extracurricular tutoring education

[J]. Educational Theory and Practice, 2011(02).

[3] Yang Chun. The ethical and contractual game between teachers and students in extracurricular tutoring education

[J]. Educational Theory and Practice, 2011(02).

[4] Liu Dongzhi. Standardized Management of Extracurricular Tutoring Education [J]. Educational Theory and Practice, 2011(02).

[5] Zhu Chenchen, Liao Sisi. Based on the perspective of collaborative governance: the realistic dilemma and path selection of the construction of family education guidance model [J]. Education observation (the second half of the month), 2017(01).

[6] Bray. Confronting the Shadow Education System-What Government Policies for What Private Tutoring? [J]. Paris: International Institute for Educational Planing, 2009.

[7] Kim, Sunwoong, Ju-Ho Lee. "Private tutoring \& demand for education in South Korea"[J]. Economic Development \& Cultural Change, 2010.

[8] David P. Baker, Motoko Akiba, Gerald K. LeTendre, Alexander W. Wiseman. Worldwide Shadow Education: Outside-School Learning, Institutional Quality of Schooling, and Cross-National Mathematics Achievement [J]. Educational Evaluation and Policy Analysis, 2001.

[9] Iveta Silova. Private tutoring in Eastern Europe and Central Asia: policy choices and implications [J]. Compare: A Journal of Comparative and International Education, 2009.

[10] Zhang Ran, Yao Jinju. Legal Regulations for Public School Teachers to Pay for Compensation: American Experience and Its Implications for China [D]. Peking University Education Review, 2017(02)

[11] Xiong Mingchuan. Rethinking the in-service teachers' "paid lessons" [J]. Teaching and Managemen, 2018(27)

[12] Luo Chaomeng. The legal and policy basis of foreign public primary and secondary school teachers' part-time work and its enlightenment [J]. Shanghai Education and Research, 2009(01) 